\title{
Black Art Posters, an Incentive to Increase Study Enrollment among Blacks in a Large Cohort Study
}

\author{
Antronette K. Yancey ${ }^{1}$, R. Patti Herring ${ }^{2}$, Gary E. Fraser ${ }^{3}$, Ru Yan ${ }^{3}$, Phyllip Baker ${ }^{2}$, Andrew \\ Lampkin $^{4}$, and James Kyle ${ }^{5}$ \\ 1 Department of Health Services and Center to Eliminate Health Disparities, UCLA School of Public Health \\ 2 Department of Health Promotion and Education, Loma Linda University School of Public Health \\ 3 Department of Epidemiology and Biostatistics, Loma Linda University School of Public Health \\ 4 School of Religion, Loma Linda University \\ 5 Charles R. Drew University of Medicine and Science
}

\section{Abstract}

Objective-Black art posters were offered to replace or augment the established $\$ 10$ incentive for questionnaire completion in a longitudinal cohort study.

\begin{abstract}
Method-81 churches located in the US southern region were divided between two intervention groups, with a control group of 24 churches from the same region. Primary outcome measures were study enrollment rates and questionnaire return rates between December 2003 and July 2004 as a proportion of church goal.
\end{abstract}

Results-9.3\% of participants returning questionnaires selected a poster in preference to $\$ 10$. Half of participants offered both monetary and art incentives indicated a poster selection. Crude questionnaire return rates were $57.4 \%$ for the pooled intervention churches and $38.2 \%$ for the control churches. Enrollment rates among those offered both incentives were significantly higher $(p<0.01)$ than when monetary incentives alone were offered after adjustment for church size, promotional dates, and average income of church members. Survey return rates were also higher in the churches offered both incentives $(\mathrm{p}=0.04)$.

Conclusion-These data suggest that the black art posters improved study enrollment and survey return rates. The relatively low rate of poster selection suggests that the art primarily influenced participation indirectly, by creating a more culturally inclusive image of the study.

\section{Keywords}

recruitment; minority; ethnic; African American; research; cohort study

\footnotetext{
Corresponding Author: Antronette K. Yancey, MD, MPH, UCLA School of Public Health, 31-235 CHS, 650 Charles Young Dr. South, Los Angeles, CA 90095, T: 310/794-9284, F: 310/206-3566, E: E-mail: ayancey@ucla.edu.

Publisher's Disclaimer: This is a PDF file of an unedited manuscript that has been accepted for publication. As a service to our customers we are providing this early version of the manuscript. The manuscript will undergo copyediting, typesetting, and review of the resulting proof before it is published in its final citable form. Please note that during the production process errors may be discovered which could affect the content, and all legal disclaimers that apply to the journal pertain.
} 


\section{Introduction}

Under-representation of African Americans in public health research contributes to a lack of understanding of health disparities, and a paucity of culturally relevant solutions.(Beech and Goodman, 2004, Ford, et al., 2005, Ness, et al., 1997) Few studies have tested the efficacy of targeted recruitment strategies, and most examine recruitment to intervention trials, rather than observational epidemiological studies.(Yancey, et al., 2006)

The Adventist Health Study (AHS-2) is a NCI-funded cohort study conducted by Loma Linda University (LLU) that initially aimed to recruit 35,000 Blacks and 70,000 Whites and other racial/ethnic groups from the US and Canada. A detailed description of the study design and cohort profile has been published elsewhere. (Butler, et al., 2007) Despite proactive investment in culturally targeted recruitment, accrual of Black participants has proceeded more slowly than that of Whites. Additional telephone follow-up 6 weeks after enrollment was found to increase questionnaire return rates among Blacks but not Whites. Although subsequently implemented for all Black enrollees, these calls are labor intensive and, hence, costly.(Bell, et al., 2005) Between January 2002 and December 2003, a total of 56.4\% of the goal for Blacks $(19,737)$ had enrolled by completing study registration postcards, but only $26.7 \%$ (9345) had returned study questionnaires; a similar $55.4 \%$ of the goal for Whites $(38,794)$ had completed postcards, but $43 \%$ more $(37.3 \%$ or 26,106$)$ had returned questionnaires.

A novel incentive strategy, Black art posters, was developed not only as a direct means of influencing response rates, but also to create and promote a more culturally inclusive image for AHS-2/LLU. This paper describes incentive development, presents supportive pilot data, and estimates the costs incurred, to inform efforts to achieve meaningful sample diversity.

\section{Methods}

\section{Church and congregant characteristics}

The South Atlantic Conference (SAC) selected for the study encompasses Georgia, North Carolina and South Carolina. The number of bulletins printed for distribution during weekly services was used as an index of attendance (membership rosters were unreliable), and varied from 7-700. Congregants are disproportionately female (65-70\%), and overwhelmingly Black (95\%). Congregant socioeconomic status (SES) is typically not highly correlated with that of the mostly lower SES areas surrounding the churches.

\section{Recruitment protocol overview}

Details of AHS-2 recruitment procedures have been published elsewhere.(Bell, et al., 2005, Butler, et al., 2007, Herring, et al., 2004) Briefly, a proactive and proportionately more costly investment was made in culturally targeted recruitment of Black participants. Given the history of racial segregation among Seventh Day Adventists, as is the case with many other US faith traditions, active engagement of the Black regional conference administration was a key element of recruitment. This was accomplished through financial incentives for pastors, and through marketing and training activities by study staff at regional meetings involving church leadership, individual pastors and "health ministry" heads. "Viral" (person-to-person) marketing was also promoted in partnership with Oakwood College, an historically Black Adventist institution. Culturally targeted "direct" marketing to Black Adventists was also conducted through mailed recruitment brochures and videos, and announcements in Adventist publications. A separate national study advisory committee was convened to shape Black recruitment strategies, in addition to the overall study advisory committee. The study was promoted by trained lay personnel in each of 800 black Adventist congregations across the US. 
Following on-site training in both Black and White churches by study staff, pastors gave motivational sermons and included reminders/health testimonials during announcement periods in church services over 3-6 weeks pre-launch. Upon enrollment, participants completed a registration card that was then mailed back to the study. At the same time, Black members were handed study questionnaires at church, to be completed and mailed back within 3 weeks. Three reminder cards were mailed to participants where necessary over the next $3-$ 4 months, and a reminder phone call was placed after 6 weeks. Recruitment of study participants in predominantly White churches proceeded somewhat differently. Registration cards only were distributed in church, and following their return, the study staff mailed questionnaires to White participants' homes, again to be returned to LLU by mail. Reminder cards were mailed as necessary. LLU's institutional review board approved all procedures.

\section{Alternative incentive development}

Grounded in social cognitive theory (Bandura, 2004) and social marketing principles, (Grier and Bryant, 2005), the art incentive linked culturally congruent images to study participation. The idea was vetted and supported by both national study advisory committees. Paintings by a local artist with ties to a study co-investigator were evaluated by study staff and selected church members for their consistency with study aims and conservative church doctrine. For example, some of the more attractive works were rejected because subjects wore jewelry, or because overweight subjects might be perceived as stereotypical or unhealthy. The artist/ graphic designer created and duplicated two high-quality $18^{\prime \prime} \times 25^{\prime \prime}$ posters, featuring spiritually-targeted captions coined by study staff, LLU and Oakwood College logos, and the poster series title, "Our health...our heritage."

\section{Incentive implementation}

Twenty-five SAC churches whose study launch dates were scheduled in February 2004 (Black History Month) were initially selected as the intervention group. Samples of the artwork were circulated during on-site study training sessions, and the interest generated prompted an increase in church representatives scheduling their study launch dates during February from 25 to 62. Stickers showing color copies of the two artworks were applied to the back of each questionnaire to permit selection of an incentive, art or $\$ 10$. Posters or checks were mailed to participants' homes after completed questionnaires were received.

Following the initial February launch, 19 additional intervention churches in the SAC with launch dates scheduled during April-June 2004 were added. Members were offered both a poster and $\$ 10$.

\section{Study design}

The study design is non-randomized and quasi-experimental. Three groups launching recruitment at different times were included: (1) 62 churches offered art or $\$ 10$ (February 2004); (2) 19 churches offered art and $\$ 10$ (April-June 2004); and (3) 24 church controls offered only $\$ 10$, launching recruitment in December 2003, March and July 2004. We adjusted the statistical model for timing, thereby estimating the effect of the artwork independent of confounding by launch timing (a proxy for study enthusiasm).

Because of the different barriers and facilitators associated with each, primary outcomes included both study enrollment (questionnaire request by submitting postcards) and questionnaire return rates within 6-8 months post-launch. Such factors include the greater time and difficulty involved in completing extensive questionnaires for low-literacy individuals, and the greater salience of $\$ 10$ to low-income individuals. 


\section{Data analysis}

In multivariate analyses the unit of observation was the church, and the outcomes of interest were ratios. The ratio of number of questionnaires returned divided by the goal $(\mathrm{G})$ for a particular church and the ratio of number of questionnaires distributed divided by goal may both substantially exceed 1.0. Thus, Poisson regression was used here.

To adjust for possible confounders, independent variables were size of church, time elapsed (delay) between promotion starting in that church and initiation of recruitment activities in the region, and estimated church SES (median income of church members based on their residential zip codes). Incentive (artwork $/ \$ 10$ ) status was indicated by two dummy variables with the reference status being the churches offered the standard \$10 incentive alone.

In the effect estimates presented, all covariates aside from the exposure of interest are fixed at given midrange values. The logarthmic link function in Poisson regression results in a predicted value of the outcome ratio. A dispersion parameter, $\sigma_{d}^{2}$ was calculated,(McCullagh and Nelder, $1983)$ and the test of statistical significance for coefficient $\beta$ is given by $\hat{\beta} /\left[\operatorname{se}(\beta) \cdot \sigma_{d}\right]$.

\section{Preliminary Cost Calculations}

Costs were estimated from budgets, invoices and other billing records.

\section{Results}

\section{Sociodemographic characteristics of churches}

Churches offered "art $\$ 10$ " were, on average, somewhat smaller in size (bulletins printed averaged 67, compared with 98 and 132 for the "art alone" and "\$10 alone" groups, respectively). They also had slightly lower mean incomes (\$45331, vs. \$48078 and \$48109, respectively) and their study promotion occurred about 1-2 months later. The multivariate analyses below adjusted for these differences.

\section{Incentive selection}

Within the 62 February intervention churches, $90.7 \%$ of members selected the $\$ 10$ monetary incentive, while 9.3\% (284) chose the poster instead. About half of those offered both art and monetary incentives indicated a poster selection. Members choosing posters instead of or as a supplement to $\$ 10$ did not differ from those not choosing posters by age group or gender.

\section{Enrollment and questionnaire return outcomes}

From the 105 churches in the study, 2707 questionnaires were returned within 8 months, 1741 from the "art or $\$ 10$ " group, 362 from the "art $+\$ 10$ " group and 604 from the " $\$ 10$ alone" group. The art incentive apparently increased the number of requests for questionnaires as a proportion of goal by approximately $50 \%$ (Table 1 ). While the art did not increase the proportion of these returned, the larger number of requests increased overall Returns/Goal. These results were essentially unchanged in multivariate analyses where all three outcomes were investigated separately, except that Returns/Goal appear substantially greater for "art $+\$ 10$ " (by $88 \%$ ) than "art alone" in the multivariate analyses (Table 2). Higher SES did not affect the likelihood of requesting questionnaires, but was associated with reduced rates of questionnaire return $(\mathrm{p}<0.001)$.

\section{Alternative incentive costs}

Licensing the artwork, and design and production of the two posters cost $\$ 3000$. Duplication costs for 2500 posters, and 3000 promotional flyers and color ordering labels were $\$ 4000$. 
Reproductions of the poster were distributed for approximately $\$ 5$ per copy mailed, including duplication, mailing tubes, address labels and postage.

\section{Discussion}

The results of this pilot test are consistent with the hypothesis that artwork delivers a culturally meaningful augmentation of monetary incentives. The higher rates of questionnaire requests in intervention vs. control churches, despite low rates of poster selection, suggests two mechanisms of influence-indirect (favorable influence on church staff's perceptions of the study resulting in greater effort in motivating congregants) and direct (positive influence on prospective participants' perceptions of the study, increasing willingness to participate regardless of incentive preference). A preference for the art may have been diminished by the unavailability, at the time, of more colorful and appealing pieces of artwork consistent with conservative church values.

The cost of obtaining additional participants by other means (re-promotion or expansion) is conservatively estimated at $\$ 50 /$ response. If about half of study participants choose a poster (along with \$10), and if the art incentive intervention results, conservatively, in 50\% greater returns, this incentive would be quite cost-effective.

SES was negatively associated with the proportion of questionnaire returns after the instrument was requested, unlike the more usual experience of lesser participation among those of lower SES. It is possible that individuals of lower SES who are not impoverished have fewer competing demands than their higher SES counterparts, and fewer barriers than the poor (e.g., lack of transportation or child care). Given the strikingly lower SES among minorities compared with whites, and that most research subjects and investigators of any ethnicity are middle class or affluent, such incentives are worthy of further investigation as strategies for increasing SES sample diversity.

A number of limitations are inherent in this study design. Non-random selection of churches results in non-equivalence of controls and introduces systematic biases. This is offset by adjustment for covariates and inter-group comparisons of participant sociodemographic data, but cannot be completely discounted. The use of control churches from the same conference that had recruited before, during, and after the periods of recruitment of intervention churches should have adequately adjusted for timing as a confounder. In addition, it is not possible to disentangle the effects of the black art incentive's artistic grounding in black culture from the effects of the conservative church values depicted in the artwork.

These supportive data speak to the possible utility and modest cost of such novel, culturally targeted approaches. A more rigorous test of such incentives is indicated.

\section{Acknowledgments}

This research was supported by NIH grant \# R01 CA94594. The authors wish to thank Hanni Bennett and Danielle Osby for their assistance in the preparation of this manuscript.

\section{References}

Bandura A. Health promotion by social cognitive means. Health Educ Behav 2004;31:143-64. [PubMed: 15090118]

Beech, BM.; Goodman, M. Race \& Research: Perspectives on Minority Participation in Health Studies. Amer Public Health Assn; Washington, DC: 2004.

Bell LS, Butler TL, Herring RP, Yancey AK, Fraser GE. Recruiting Blacks to the Adventist Health Study: Do Follow-up Phone Calls Increase Response Rates? Ann Epidemiol. 2005 
Butler TL, Fraser GE, Beeson WL, Knutsen SF, Herring RP, Chan J, Sabate J, Montgomery S, Haddad E, Preston-Martin S, Bennett H, Jaceldo-Siegl K. Cohort profile: The Adventist Health Study-2 (AHS-2). Int J Epidemiol. 2007

Ford JG, Howerton MW, Bolen S, Gary TL, Lai GY, Tilburt J, Gibbons MC, Baffi C, Wilson RF, Feuerstein CJ, Tanpitukpongse P, Powe NR, Bass EB. Knowledge and access to information on recruitment of underrepresented populations to cancer clinical trials. Evid Rep Technol Assess (Summ) 2005:1-11.

Grier S, Bryant CA. Social marketing in public health. Annu Rev Public Health 2005;26:319-39. [PubMed: 15760292]

Herring P, Montgomery S, Yancey AK, Williams D, Fraser G. Understanding the challenges in recruiting blacks to a longitudinal cohort study: the Adventist health study. Ethn Dis 2004;14:423-30. [PubMed: 15328945]

McCullagh, P.; Nelder, JA. Generalized linear models. (Monographs on statistics and applied probability). Chapman and Hall; London; New York: 1983. p. xiii-261.

Ness RB, Nelson DB, Kumanyika SK, Grisso JA. Evaluating minority recruitment into clinical studies: how good are the data? Ann Epidemiol 1997;7:472-8. [PubMed: 9349914]

Yancey AK, Ortega AN, Kumanyika SK. Effective recruitment and retention of minority research participants. Annu Rev Public Health 2006;27:1-28. [PubMed: 16533107] 
Table 1

Percentages of questionnaires distributed and returned for enrollment in a cohort study. Southern United States, 2003-2004.

\begin{tabular}{lccc} 
& Art $+\$ \mathbf{1 0}$ & Art Alone & \$10 Alone \\
& $\%$ & $\%$ & $\%$ \\
\hline $\begin{array}{l}\text { Primary Outcome Measures } \\
\text { Questionnaires Distributed as Percentage of Church Goal for Returns } \\
83.6\end{array}$ & 92.6 & 67.3 \\
Questionnaires Returned as Percentage of Church Goal for Returns & 57.1 & 38.2 \\
Secondary Outcome Measure $\quad 58.4$ & & 56.7 \\
Questionnaires Returned as Percentage of those Distributed & 61.5 & \\
\hline
\end{tabular}


Table 2

Predictors of the number of questionnaires returned as a proportion of the goal for that church for enrollment in a cohort study. Southern United States, 2003-2004.

\begin{tabular}{|l|l|l|l|}
\hline Variable & Beta-coefficient & Standard Error $\boldsymbol{S E}(\widehat{\beta})$ & Effect size $^{\text {* }}$ (95\% Confidence Interval) \\
\hline Constant & 0.730 & 0.502 & - \\
\hline Delay in Promotion (Months) & -0.224 & 0.071 & $0.80(.70-.92)$ \\
\hline Goal/50 & -0.045 & 0.050 & $0.96(.87-1.05)$ \\
\hline Income $\$ 10000^{\dagger}$ & -0.157 & 0.092 & $0.85(.71-1.02)$ \\
\hline Art alone & 0.049 & 0.156 & $1.05(.77-1.43)$ \\
\hline Art $+\$ 10$ & 0.512 & 0.237 & $1.67(1.05-2.66)$ \\
\hline
\end{tabular}

For continuous variables, the ratio of the proportion at two levels of the variable of interest, one unit apart.

Covariates and the baseline value of the variable of interest are fixed at zero delay in promotion; goal=50; household income $=\$ 40,000$; "art alone" $=0$, "art $+\$ 10$ ' $=0$, so the incentive is set at the reference condition of $\$ 10$ alone when the variable of interest is a non-incentive variable.

${ }^{\dagger}$ Household income. The correlation between aggregate congregant socioeconomic status estimates from residential zip codes of those returning questionnaires and similar estimates derived from self-reported household income was 0.37 ( $\mathrm{p}<0.001)$.

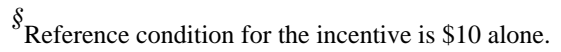

